\title{
HIGH BODY-MASS INDEX IS NOT ASSOCIATED WITH WORSE CLINICOPATHOLOGICAL CHARACTERISTICS IN PREDOMINANTLY OBESE BREAST CANCER PATIENTS
}

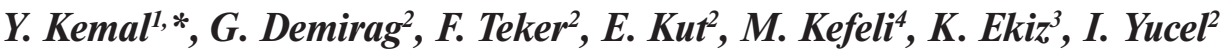 \\ ${ }^{1}$ Samsun Education and Research Hospital, Department of Medical Oncology, Samsun 55100, Turkey \\ ${ }^{2} 19$ Mayis University, Faculty of Medicine, Department of Medical Oncology, Samsun 55270, Turkey \\ ${ }^{3} 19$ Mayis University, Faculty of Medicine, Department of Internal Medicine, Samsun 55270, Turkey \\ ${ }^{4} 19$ Mayis University, Faculty of Medicine, Department of Pathology, Samsun 55270, Turkey
}

Background: Breast cancer (BC) is the most common cancer among women. A high body-mass index (BMI) is related to increased incidence of $\mathrm{BC}$ with poorer prognosis. Aim: The aim of the study was to evaluate the association in patients with $\mathrm{BC}$ between $\mathrm{BMI}$ at the time of diagnosis and biological characteristics, according to the menopausal status. Materials and Methods: This retrospective study comprised a total of 318 women with BC. Clinicopathological differences between normal, overweight and obese patients according to menopausal status were evaluated. Results: Premenopausal women had a significantly lower BMI than postmenopausal patients (28.7 vs. 31.5 , respectively; $p=0.00001)$. No statistically significant association was determined between BMI and clinicopathological characteristics in either the premenopausal or the postmenopausal group (all p values are $>0.05$ ). Conclusions: There are many conflicting results in literature on this relationship. The results of this study showed that a high BMI is not associated with worse clinicopathological characteristics in a predominantly obese population. In current medical oncology practice, BC should be evaluated on an individual patient basis and the impact of obesity on $\mathrm{BC}$ prognosis seems to be difficult to estimate especially in an obese population.

Key Words: breast cancer, body-mass index, prognosis.

Breast cancer $(\mathrm{BC})$ is the most frequent invasive neoplasm in women. It has been estimated that by 2015 the annual global incidence of BC will be 1.6 million women [1]. The impact of both genetic and environmental risk factors on BC etiology has been well established. Positive associations of reproductive risk factors such as early menarche, late menopause, nulliparity, hormone replacement therapy and postmenopausal obesity are reportedly stronger for estrogen receptor (ER)-positive $\left(E R^{+}\right)$than for ER-negative (ER-) BC [2, 3]. However, the prevelance of obesity has increased dramatically and if current trends continue, over $50 \%$ of the world's population will be obese by the year 2030 [4].

Besides its established role as a risk factor, there is now widespread consensus on the importance of obesity as a negative prognostic factor for $B C[5,6]$. $B C$ is, however, a biologically heterogeneous disease and definitive evidence is still lacking on the impact of obesity on prognosis. Some authors [7] have found that obese women develop BC with a significantly higher proliferation index, nuclear grade and larger size compared to normal and underweight women. It has also been suggested that obesity at diagnosis is associated with a higher number of metastatic axillary nodes [8]. According to the data from an ATAC (anastrozole, tamoxifen, alone, or in combination) trial, postmenopausal women with high body-mass index (BMI) treated with anastrozole showed significantly more distant recurrences than those with a low BMI [9].

Submitted: July 02, 2015.

${ }^{\star}$ Correspondence: E-mail: drturkmen@yahoo.com

Tel.: 090362316000-1135; Fax: 0903622330917.

Abbreviations used: BC - breast cancer; BMI - body-mass index; ER - estrogen receptor; PR - progesterone receptor.
Furthermore, Berclaz et al. [10] demonstrated that elevated BMI is significantly associated with a worse prognosis, especially for pre- and perimenopausal patients. Consistent with these studies, Kawai et al. [11] found that higher BMI was associated with an increase in mortality for premenopausal patients. Their analysis of subgroups showed a positive association between higher BMI and a worse prognosis for patients with hormonal receptor-positive tumors. Thus, the effect of $B M I$ on $\mathrm{BC}$ incidence and prognosis seems to be restricted to ER-positive BC. However, it is not yet clear why prognosis mostly correlates with the BMI of premenopausal patients. If the occurrence of $B C$ in patients with high $\mathrm{BMI}$ is the result of an increase in estrogen status, these tumors must be highly estrogen dependent, thus resulting in a favorable prognosis. However, a poorer prognosis for patients with high BMI may indicate that BMI plays a significant part in $\mathrm{BC}$ etiology and prognosis by mediation through various mechanisms.

The exact reason remains unclear, but different hypotheses have been suggested to explain the poorer survival in obese women. For example, obese women undergo less screening [12] so tend to have more advanced disease at presentation, they have an increased risk of developing second primary cancer [13], obese women develop more complications and toxicity due to chemotherapy [14] and have more aggressive tumors [15]. To determine the crucial role of BMI, the relationship between tumor biological characteristics and the $\mathrm{BMI}$ of patients, therefore needs more attention, as to date there have been very few studies on this subject in literature.

The aim of this study was to analyze the association between $\mathrm{BMI}$ at the time of diagnosis and biological 
characteristics in BC patients, focusing specifically on $\mathrm{ER}, \mathrm{PR}$, and stage according to menopausal status.

\section{MATERIALS AND METHODS}

The study comprised 318 cases of invasive $\mathrm{BC}$ treated with mastectomy or breast-conserving surgery at 19 Mayis University Hospital between 2008 and 2012. Approval for the study was granted by the Ethics Committee of 19 Mayis University; approval number: $2012 / 502$. Detailed information was obtained from the electronic database of the patient archives.

Patient weight and height were recorded before surgery and the BMI is calculated based on the following formula:

$B M I=$ bodyweight $(\mathrm{kg}) /$ height $^{2}\left(\mathrm{~m}^{2}\right)$.

Women were categorized according to the WHO criteria: underweight $-\mathrm{BMI}<19 \mathrm{~kg} / \mathrm{m}^{2}$; normal $\mathrm{BMI} \geqslant 19$ and $<25 \mathrm{~kg} / \mathrm{m}^{2}$; overweight $-\mathrm{BMI} \geqslant 25$ and $<30 \mathrm{~kg} / \mathrm{m}^{2}$; obese - BMI $\geqslant 30 \mathrm{~kg} / \mathrm{m}^{2}$.

Menopausal status was defined by 1 year of amenorrhea, or previous bilateral oophorectomy. Pathologic tumor grade, estrogen and progesterone receptor (ER and PR) expression, tumor size, lymph node metastasis and HER-2/neu status were recorded from the electronic patient database for statistical evaluation.

Immunohistochemical staining. All the tumor tissues were fixed in formalin and then embedded in paraffin. Tissue sections were cut at 3-4 $\mu \mathrm{m}$ for immunohistochemical staining. Immunohistochemical staining and in situ hybridisation were performed using the Ventana BenchMarkXT autostaining system (Ventana Medical Systems, Tucson, AZ, USA). ER (Clone 6F11, Novocastra) and PR (Clone 16, Novocastra) antibodies were used and a value of $>1 \%$ was accepted as positive. For HER-2 positivity, 3+ HER-2 (Clone CB-11, Biogenex) immunohistochemical staining or a positive HER-2 silver in situ hybridization (SISH) test was accepted as HER-2 positive.

Statistical analysis. Statistical analysis were performed using SPSS software for Windows, version 15. In all tests, $\mathrm{p}<0.05$ was considered statistically significant. The association between BMl and BC characteristics (nuclear grade, ER and PR expression, tumor size, lymph node metastasis and HER-2/neu status) was determined using the $\chi^{2}$ test (we hypothesized the effect of BMI on prognostic and predicting clinicopathological tumor features).

\section{RESULTS}

A total of 318 women with BC were enrolled in this retrospective study. The mean age of the study participants was $50.0 \pm 9.7$ years (range $27-77$ years). Of the total patients, 156 were premenopausal and 162 were postmenopausal. The premenopausal women had a significantly lower BMI than the postmenopausal women (28.7 vs. 31.5, respectively; $p=0.00001$ ) (Table 1). A total of $78 \%$ of premenopausal women were classified as overweight/obese, while, in the postmenopausal group, nearly all the patients (92\%) were overweight/obese (Table 2).
Table 1. Relationship between BMI and menopausal status of $B C$ patients

\begin{tabular}{lccc}
\hline Characteristics & $\begin{array}{c}\text { Premenopausal, } \mathrm{n}(\%) \\
\mathrm{N}=156\end{array}$ & $\begin{array}{c}\text { Postmenopausal, } \mathrm{n}(\%) \\
\mathrm{N}=162\end{array}$ & $\mathrm{p}$ value \\
\hline $\mathrm{Age}^{1}(\mathrm{years})$ & $43.1(6.2)$ & $56.5(7.8)$ & \\
$\mathrm{BMI}^{\left(\mathrm{kg} / \mathrm{m}^{2}\right)}$ & $28.7(4.9)$ & $31.5(5.3)$ & 0.00001 \\
\hline
\end{tabular}

Note: ${ }^{1}$ Mean (Standard deviation).

Table 2. BMl distribution

\begin{tabular}{lccc}
\hline \multicolumn{1}{c}{ BMI distribution } & $\begin{array}{c}\text { Premenopausal } \\
\text { women, } \mathrm{n}(\%) \\
\mathrm{N}=156\end{array}$ & $\begin{array}{c}\text { Postmenopausal } \\
\text { women, } \mathrm{n}(\%) \\
\mathrm{N}=162\end{array}$ & $\mathrm{p}$ value $\left(\mathrm{X}^{2}\right.$ test $)$ \\
\hline $\begin{array}{l}\text { Normal weight } \\
(19<\mathrm{BMl}<24.9)\end{array}$ & $36(22.1)$ & $13(8.0)$ & \\
$\begin{array}{l}\text { Overweight } \\
(25<\mathrm{BMl}<29.9)\end{array}$ & $54(35.0)$ & $51(31.5)$ & 0.001 \\
$\begin{array}{l}\text { Obese } \\
(\mathrm{BMI}>30)\end{array}$ & $66(42.9)$ & $98(60.5)$ & \\
\hline
\end{tabular}

Correlation between BMI and clinicopathological characteristics of $\mathbf{B C}$. The patients were divided into three groups based on $\mathrm{BMl}$; the normal weight group (BMl smaller than $24.9 \mathrm{~kg} / \mathrm{m}^{2}$ ) comprised 49 patients, the overweight group (BMl between 25 and $30 \mathrm{~kg} / \mathrm{m}^{2}$ ) 105 patients and the obese group (BMl $>30 \mathrm{~kg} / \mathrm{m}^{2}$ ) 164 patients.

In both the premenopausal and the postmenopausal group no statistically significant association was determined between $\mathrm{BMI}$ and clinicopathological characteristics (all $p>0.05$ ) (Table 3, 4).

Table 3. Relationship between BMI and clinicopathological characteristics in premenopausal patients

\begin{tabular}{lcccc}
\hline Characteristics & $\begin{array}{c}\text { Normal } \\
\text { weight, } \mathrm{n}(\%) \\
\mathrm{N}=34^{*}\end{array}$ & $\begin{array}{c}\text { Overweight, } \\
\mathrm{n}(\%) \\
\mathrm{N}=54\end{array}$ & $\begin{array}{c}\text { Obese, } \\
\mathrm{n}(\%) \\
\mathrm{N}=66\end{array}$ & p value \\
\hline Nuclear grade & & & & \\
1 & $1(2.9)$ & $5(9.3)$ & $8(12.1)$ & 0.221 \\
2 & $27(79.4)$ & $32(59.3)$ & $45(68.2)$ & \\
3 & $6(17.6)$ & $17(31.5)$ & $13(19.7)$ & \\
Tumor size & $8(23.5)$ & $20(37.0)$ & $26(39.4)$ & \\
1 & $20(58.8)$ & $25(46.3)$ & $29(43.9)$ & 0.767 \\
2 & $4(11.8)$ & $7(13.0)$ & $9(13.6)$ & \\
3 & $2(5.9)$ & $2(3.7)$ & $2(3.0)$ & \\
4 & & & & \\
Lymph node metastasis & $13(38.2)$ & $20(37.0)$ & $30(45.5)$ & 0.627 \\
Negative & $21(61.8)$ & $34(63.0)$ & $36(54.5)$ & \\
Positive & & & & \\
ER & $28(82.4)$ & $36(66.7)$ & $49(74.2)$ & 0.263 \\
ER & $6(17.6)$ & $18(33.3)$ & $17(25.8)$ & \\
ER & & & & \\
PR $^{+}$ & $21(61.8)$ & $31(57.4)$ & $42(63.6)$ & 0.781 \\
PR $^{+}$ & $13(38.2)$ & $23(42.6)$ & $24(36.4)$ & \\
PR $^{-}$ & & & & \\
HER2 & $8(23.5)$ & $21(38.9)$ & $14(21.2)$ & 0.081 \\
Positive $_{\text {Negative }}$ & $26(76.5)$ & $33(61.1)$ & $52(78.8)$ & \\
\hline
\end{tabular}

Note: *grade and other characteristics are reached 34 of 36 patients.

\section{DISCUSSION}

Consistent with many previous studies, the results of this study have shown that the BMI of postmenopausal patients was significantly higher than that of premenopausal patients. The strength of this study is the homogeneity in patient management as all the patients were treated and detected in a single institution. However, no significant association was determined between $\mathrm{BC}$ characteristics and the BMI of the patients in the study group. 
Table 4. Relationship between BMI and clinicopathological characteristics in postmenopausal patients

\begin{tabular}{|c|c|c|c|c|}
\hline Characteristics & $\begin{array}{c}\text { Normal } \\
\text { weight, } n(\%) \\
N=13\end{array}$ & $\begin{array}{c}\text { Overweight, } \\
n(\%) \\
N=51\end{array}$ & $\begin{array}{c}\text { Obese, } \\
n(\%) \\
N=98\end{array}$ & $p$ value \\
\hline \multicolumn{5}{|l|}{ Nuclear grade } \\
\hline 1 & $1(7.7)$ & $9(17.6)$ & $17(17.3)$ & \multirow{3}{*}{0.375} \\
\hline 2 & $6(46.2)$ & $31(60.8)$ & $60(61.2)$ & \\
\hline 3 & $6(46.2)$ & $11(21.6)$ & $21(21.4)$ & \\
\hline \multicolumn{5}{|l|}{ Tumor size } \\
\hline 1 & $3(23.1)$ & $19(37.3)$ & $42(42.9)$ & \multirow{4}{*}{0.745} \\
\hline 2 & $8(61.5)$ & $28(54.9)$ & $45(45.9)$ & \\
\hline 3 & $1(7.7)$ & $3(5.9)$ & $8(8.2)$ & \\
\hline 4 & $1(7.7)$ & $1(2.0)$ & $3(3.1)$ & \\
\hline \multicolumn{5}{|c|}{ Lymph node metastasis } \\
\hline Negative & $7(53.8)$ & 27 (52.9) & $39(39.8)$ & \multirow[t]{2}{*}{0.249} \\
\hline Positive & $6(46.2)$ & $24(47.1)$ & $59(60.2)$ & \\
\hline \multicolumn{5}{|l|}{ ER } \\
\hline $\mathrm{ER}^{+}$ & $9(69.2)$ & $40(78.4)$ & 70 (71.4) & \multirow{2}{*}{0.615} \\
\hline $\mathrm{ER}^{-}$ & $4(30.8)$ & $11(21.6)$ & $28(28.6)$ & \\
\hline \multicolumn{5}{|l|}{ PR } \\
\hline $\mathrm{PR}^{+}$ & $4(30.8)$ & $25(49.0)$ & $53(54.1)$ & \multirow{2}{*}{0.276} \\
\hline $\begin{array}{c}\mathrm{PR}^{-} \\
\text {HER2 }\end{array}$ & $9(69.2)$ & $26(51.0)$ & 45 (45.9) & \\
\hline Positive & $5(38.5)$ & $11(21.6)$ & $28(28.6)$ & 0.418 \\
\hline Negative & $8(61.5)$ & $40(78.4)$ & $70(71.4)$ & \\
\hline
\end{tabular}

Many studies in literature have investigated the association between BMI and DC. It is well-known that a high $\mathrm{BMI}$ is positively associated with increased $\mathrm{ER}\left({ }^{+}\right)$ $\mathrm{BC}$ risk in postmenopausal women due to enhanced production of circulating estrogens [16, 17]. Recently, new studies have focused on the importance of obesity as a negative prognostic factor. Some authors $[18,19]$ have found that obese women develop aggressive BC with a significantly higher number of metastatic axillary nodes, higher proliferation index, nuclear grade and larger size compared to normal and underweight women. If obesity results in more $\mathrm{BC}$ because of high estrogen levels, these tumors must be estrogen dependent with a favorable prognosis. However, various mechanisms play a role in aggressive prognosis. Overweight women have high levels of insulin-like growth factor and other growth factors such as leptin, TNF- $\alpha$, IL-6 and VEGF, which promote angiogenesis, tumor growth, metastasis and inhibit apoptosis [20].

Although $\mathrm{BC}$ is a biologically heterogeneous disease, definitive evidence is still lacking on the impact of obesity on BC prognosis. In different studies, different associations have been found between clinicopathological characteristics and BMI with no standard result reached as yet. Recently, Yanai et al. [21] reported that a high BMI showed significantly higher lymph node metastasis, and Mazzarella et al. [22] found that obesity significantly correlates with overall survival and increases distant metastasis in $\mathrm{ER}(-) /$ Her/neu-positive BC. In contrast, Biglia et al. [23] could not find any statistically significant correlation between BC subtypes and BMI in both pre- and postmenopausal patients. When planning current treatments according to molecular classification and genomic characteristics, an easy to apply factor such as BMI can be of benefit and positive research studies in support of this are undoubtedly important as obesity is a modifiable risk factor.
The results of this study did not support some previous studies which have stated that a higher BMI is associated with worse clinicopathological characteristics in BC patients. The current study population consisted of predominantly obese patients with mean $\mathrm{BMI}$ of 28.7 in the premenopausal group and 31.5 in the postmenopausal group. These values are considerably higher than those of previously reported studies. In a recent similar study by Lino-Silva et al. [24] of endometrial carcinoma in obese patients, it was reported that a high BMl is not a prognostic factor of a worse condition. However, that study did not include a high number of patients which may have been sufficient to show small but significant differences.

In conclusion, obesity, which is increasing dramatically and becoming a major global healthcare problem, is a variable risk factor for $\mathrm{BC}$. It is difficult to treat and follow obese $\mathrm{BC}$ patients because of complications and comorbidities. Cancer is different in each patient and personalized treatment should be a priority. In current clinical practice, there should be intervention against obesity although a direct relationship between $\mathrm{BMI}$ and simple clinical and pathological characteristics was not determined. $\mathrm{BC}$ is a heterogeneous disease and the impact of obesity on BC prognosis seems to be difficult to estimate. Future studies are needed to evaluate the relationship between molecular characteristics of $\mathrm{BC}$ and $\mathrm{BMI}$.

\section{ACKNOWLEDGEMENT}

The authors thank Dr. Berkhan Topaktas for advice on the statistical analyses of the study.

\section{REFERENCES}

1. Ferlay J, Shin HR, Bray F, et al. GLOBOCAN 2008 v2.0, Cancer Incidence and Mortality Worldwide: IARC CancerBase No. 10. Lyon, France: International Agency for Research on Cancer; 2010 (http://globocan.iarc.fr).

2. Althuis MD, Fergenbaum JH, Garcia-Closas M, et al. Etiology of hormone receptor-defined breast cancer: a systematic review of the literature. Cancer Epidemiol Biomarkers Prev 2004; 13: 1558-68.

3. Ma H, Bernstein L, Pike MC, Ursin G. Reproductive factors and breast cancer risk according to joint estrogen and progesterone receptor status: a meta-analysis of epidemiological studies. Breast Cancer Res 2006; 8: R43.

4. Kelly T, Yang W, Chen CS, et al. Global burden of obesity in 2005 and projections to 2030. Int J Obes 2008; 32: $1431-37$.

5. Ewertz M, Jensen MB, Gunnarsdottir KA, et al. Effect of obesity on prognosis after early-stage breast cancer. J Clin Oncol 2011; 29: 25-31.

6. Protani M, Coory M, Martin JH. Effect of obesity on survival of women with breast cancer: systematic review and meta-analysis. Breast Cancer Res Treat 2010; 123: 627-35.

7. Daling JR, Malone KE, Doody DR, et al. Relation of body mass index to tumor markers and survival among young women with invasive ductal breast carcinoma. Cancer 2001; 92: 720-9.

8. Loi S, Milne RL, Friedlander ML, et al. Obesity and outcomes in premenopausal and postmenopausal breast cancer. Cancer Epidemiol Biomarkers Prev 2005; 14: 1686-91.

9. Sestak I, Distler W, Forbes JF, et al. Effect of body mass index on recurrences in tamoxifen and anastrozole treated 
women: an exploratory analysis from the ATAC trial. J Clin Oncol 2010; 28: 3411-5.

10. Berclaz G, Li S, Price KN, et al. Body mass index as a prognostic feature in operable breast cancer: the International Breast Cancer Study Group experience. Ann Oncol 2004; 15: 875-84.

11. Kawai M, Minami Y, Nishino Y, et al. Body mass index and survival after breast cancer diagnosis in Japanese women. BMC Cancer 2012; 12: 149.

12. Wee CC, McCarthy EP, Davis RB, et al. Obesity and breast cancer screening. J Gen Intern Med 2004; 19: 324-31.

13. Li CI, Daling JR, Porter PL, et al. Relationship between potentially modifiable lifestyle factors and risk of second primary contralateral breast cancer among women diagnosed with estrogen receptor-positive invasive breast cancer. J Clin Oncol 2009; 27: 5312-8.

14. Griggs JJ, Sorbero MES, Lyman GH. Undertreatment of obese women receiving breast cancer chemotherapy. Arch Intern Med 2005; 65: 1267-73.

15. Cui Y, Whiteman MK, Flaws JA, et al. Body mass and stage of breast cancer at diagnosis. Int $\mathbf{J}$ Cancer 2002; 98: $279-83$.

16. Renehan AG, Tyson M, Egger M, et al. Body-mass index and incidence of cancer: a systematic review and meta-analysis of prospective observational studies. Lancet 2008; 371: 569-78.

17. Harvie M, Hooper L, Howell AH. Central obesity and breast cancer risk: a systematic review. Obes Rev 2003; 4: 157-73.
18. Daling JR, Malone KE, Doody DR, et al. Relation of body mass index to tumor markers and survival among young women with invasive ductal breast carcinoma. Cancer 2001; 92: 720-9.

19. Loi S, Milne RL, Friedlander ML, et al. Obesity and outcomes in premenopausal and postmenopausal breast cancer. Cancer Epidemiol Biomarkers Prev 2005; 14: 1686-91.

20. Goodwin PJ, Ennis M, Pritchard KI, et al. Fasting insulin and outcome in early-stage breast cancer: results of a prospective cohort study. J Clin Oncol 2002; 20: 42-51.

21. Yanai A, Miyagawa $Y$, Murase $K$, et al. Influence of body mass index on clinicopathological factors including estrogen receptor, progesterone receptor, and Ki67 expression levels in breast cancers. Int J Clin Oncol 2014; 19: 467-72.

22. Mazzarella L, Disalvatore D, Bagnardi V, et al. Obesity increases the incidence of distant metastases in oestrogen receptor-negative human epidermal growth factor receptor 2-positive breast cancer patients. Eur J Cancer 2013; 49: 3588-97.

23. Biglia N, Peano E, Sgandurra P, et al. Body mass index (BMI) and breast cancer: impact on tumor histopathologic features, cancer subtypes and recurrence rate in pre- and postmenopausal women. Gynecol Endocrinol 2013; 29: 263-7.

24. Lino-Silva LS, de León DC, Salcedo-Hernández RA, et al. A high body mass index is not a worse prognostic factor for endometrial carcinoma in a predominantly obese population. Clin Transl Oncol 2013; 15: 243-7. 